\title{
UTOPIA E PSICANÁLISE EM HERBERT MARCUSE ${ }^{1}$
}

- RESUMO: Neste artigo apresentaremos uma importante idéia formulada por Marcuse na segunda parte do livro Eros e Civilização: uma interpretação filosófica do pensamento de Freud (1955) - a hipótese da transformação não repressiva das pulsões em uma sociedade transformada. Marcuse preocupa-se com a "transformação subjetiva" necessária à passagem do capitalismo para o "comunismo", rompendo assim com um determinado "marxismo ortodoxo". A "utopia" desenvolvida neste livro baseia-se na reinterpretação de algumas das principais concepções da teoria freudiana e caracteriza a originalidade de seu pensamento.

- PALAVRAS-CHAVE: Marcuse; Imaginação; Pulsões de Vida; Pulsões de Morte Memória; Utopia.

\section{Introdução}

A interpretação da teoria freudiana realizada por Marcuse em Eros e Civilização tem como proposta a ortodoxia em relação às suas categorias e conceitos: isto significa que ele não pretende acrescentar concepções exteriores à teoria freudiana, mas manter-se fiel às suas categorias, observando a possibilidade de um desenvolvimento não-repressivo das pulsões a partir dos seus próprios conceitos.

1 Este texto é uma versão resumida do capítulo três da Dissertação de Mestrado (Marcuse e Freud: uma interpretação polêmica - um estudo de "Eros e Civilização") defendida em 2002 no Programa de Pós-Graduação em Filosofia da Universidade Federal de São Carlos-UFSCar sob a orientação de Wolfgang Leo Maar e com auxilio da Fapesp.

2 Doutoranda no Programa de Pós-Graduação em Filosofia da Universidade Federal de São CarlosUFSCar sob orientação de Wolfgang Leo Maar e com auxílio do CNPq. Artigo recebido em set/06 e aprovado para publicação em nov/06. 
Não estaremos interessados aqui em apurar se de fato Marcuse se mantém fiel ou se ele deforma as categorias da teoria freudiana. Nosso objetivo é limitado e bem preciso: saber como ele desenvolve esta sua proposta.

Para Marcuse, a teoria freudiana da cultura contém uma severa crítica ao "princípio de realidade" repressivo e nesta crítica ela conduz a uma "imagem de libertação". O "pessimismo" freudiano quanto à possibilidade de felicidade e liberdade individuais levaria dialeticamente à negação e à recusa dessa sociedade repressiva. Neste sentido, nosso autor afirma que a possibilidade de uma transformação não-repressiva do "princípio de realidade" deve ser imanente às próprias concepções freudianas, deve estar contida em seus próprios conceitos. O caráter "conservador" das pulsões e a oposição destas à civilização devem desaparecer sob as condições de uma sociedade não-repressiva - é esta possibilidade vislumbrada por Marcuse que apresentaremos neste artigo.

Se, de modo geral, na primeira parte de Eros e Civilização Marcuse apresenta as principais concepções da teoria freudiana da cultura, como a teoria das pulsões, a concepção de "princípio de realidade", a teoria da formação da sociedade e da cultura entre outros, na segunda parte do livro ele se dedica à demonstração da possibilidade das pulsões percorrerem um caminho diferente sob a condição de uma realidade transformada, ou seja, de um "princípio de realidade não-repressivo" (justamente esta segunda parte que nos interessa). Segundo Marcuse são duas as justificativas desta possibilidade: a primeira eqüivale ao surgimento da sociedade industrial avançada e sua crescente produtividade; a segunda, pertence ao próprio contexto da teoria freudiana, na medida em que suas categorias e seus conceitos conduziriam à idéia de um novo "princípio de realidade".

Esta segunda possibilidade referente à imagem de uma realidade nãorepressiva presente nas próprias concepções freudianas também pertence ao contexto mais geral da filosofia ocidental: "neste ponto a metapsicologia freudiana encontra uma das principais correntes da filosofia ocidental" (Marcuse, 1963, p.102). No Intermezzo Filosófico (capítulo 5 de Eros e Civilização) Marcuse insere Freud na história da filosofia ocidental num duplo movimento: por um lado, reconhecimento da dominação instrumental (tanto do mundo interno quanto externo), que implica o estabelecimento da oposição entre a "razão" e a "sensibilidade"; por outro, a denúncia da realidade repressiva através de uma imagem de reconciliação.

A oposição entre "razão" e "sensibilidade" explicita o controle do homem sobre a natureza, que garante a realização das potencialidades humanas e que foi estabelecido mediante o Logos de dominação (as faculdades superiores) e a repressão das faculdades sensíveis e naturais. Na teoria freudiana o "trabalho socialmente útil", que garante a sobrevivência do ser humano em um mundo externo agressivo, só pode se estabelecer a partir da 
repressão e sublimação das pulsões, sobretudo das "pulsões de vida", isto é, debilitando e limitando as possibilidades de obtenção de prazer pela satisfação sexual. A repressão e sublimação das pulsões são condições necessárias ao progresso da civilização, como Freud mostra em seu texto de 1908, Moral sexual cultural e nervosidade moderna: "nossa cultura descansa totalmente na coerção das pulsões". Freud apresenta o contexto da civilização a partir da subjugação das faculdades sensíveis do ser humano, imposta pelo progresso.

Neste sentido, as concepções freudianas se assemelham às presentes em Aristóteles e Hegel. As implicações da concepção do Logos como essência do ser, presentes na lógica aristotélica, são sentidas ao longo da história da filosofia, se confundindo com uma razão que "ordena, classifica e dirige" e impõe a luta contra as faculdades receptivas e contra o princípio de prazer. Também Hegel demonstrou que a civilização só se estabelece a partir de uma "lógica da dominação" da qual depende toda liberdade e satisfação humanas: a "consciência-de-si" aparece como negação do outro e como desejo de supressão desta separação a partir da aniquilação do outro - "consciência-de-si como desejo". Com Hegel o "círculo se fecha": ele reconheceu a história da humanidade enquanto dominação e triunfo da razão, mas ao mesmo tempo apresentou esta história como terminada - "a dialética de Hegel se mantém no interior dos quadros postos pelo princípio de realidade" (idem, p.108).

Se, de um lado, estas filosofias apresentam a realidade como realidade da dominação e da repressão, de outro, elas representam a necessidade de superação desta realidade: "a lógica da dominação não triunfa sem combate" (idem, p.104). Marcuse vai mostrar que nestas teorias sobrevive a imagem de um Logos de satisfação e de uma realidade de prazer, de um mundo no qual todas as potencialidades sejam realizadas. O conteúdo dos conceitos de "liberdade" e "razão", por exemplo, estão em evidente contradição com a realidade: este abismo entre a imagem da satisfação e a realidade da não realização atua como uma crítica do "princípio de realidade" repressivo por trazer à consciência essas contradições efetivas. No entanto, a crítica se paralisa na medida em que a superação da realidade repressiva sobrevive apenas como imagem e não como possibilidade de realização efetiva.

Pois é justamente a realização desta realidade de satisfação que, para Marcuse, se tornou possível com o desenvolvimento da sociedade tecnológica. Ele tenta mostrar que, no novo contexto histórico, esses conceitos críticos, que vislumbram um novo "princípio de realidade", poderiam se realizar efetivamente: o livre desenvolvimento das potencialidades humanas não implica mais necessariamente a repressão e inibição das faculdades inferiores, que foi fundamental para a dominação da natureza a partir do Logos de dominação - não há mais necessidade de manter a separação entre 
a "razão" e a "sensibilidade", uma vez que as realizações técnicas da sociedade industrial avançada permitiriam a satisfação das necessidades básicas sem muito esforço.

Marcuse realiza uma interpretação da teoria freudiana tendo em vista a possibilidade de uma sociedade na qual as "pulsões de vida" possam se realizar e em que o trabalho não seja oposto a essa satisfação. Mas para isso ele precisa demonstrar que as "pulsões de morte" não destruiriam esta civilização, já que Freud vê em sua atividade o maior empecilho para um "princípio de realidade" não repressivo. Segundo Marcuse, as próprias concepções freudianas não negam a possibilidade da transformação nãorepressiva das pulsões, tornada possível com o desenvolvimento da civilização - ele desenvolve esta possibilidade a partir da própria teoria freudiana.

\section{A imaginação}

Marcuse busca na teoria freudiana conceitos e noções que coloquem em questão o "princípio de realidade" repressivo, que sejam sua negação e acusação. Ele destaca como um dos principais o conceito de "imaginário". Este princípio mental possui um papel muito importante na estrutura mental, na medida em que ele liga as camadas mais profundas do inconsciente à consciência: "ele guarda os arquétipos da espécie, as imagens eternas recalcadas da memória individual e coletiva, as imagens tabus de liberdade" (idem, p.128). Este modo de pensamento se acha livre do "princípio de realidade" e está em relação direta com o "princípio de prazer". É na arte que ele expressa sua forma e sua reivindicação de liberdade e satisfação, contra a realidade repressiva. Suas reivindicações de satisfação são também vistas nas "perversões", uma vez que expressam o elo entre a imaginação e sexualidade - as perversões são o resultado da luta da sexualidade reprimida pela obtenção de prazer:

Graças à revolta contra o princípio de rendimento em nome do princípio de prazer, as perversões mostram uma afinidade profunda com a imaginação. (...) Contra uma sociedade que utiliza a sexualidade como um meio para realizar um fim socialmente útil, as perversões mantêm a sexualidade como um fim em si: elas se colocam fora do reino do princípio de rendimento e colocam sua base em questão. (idem, p.54)

Neste sentido, a "imaginação" adquire um papel central nas formulações de Marcuse. Sua função crítica deriva do fato de ela evocar uma imagem de liberdade e felicidade que se opõe à realidade repressiva e que recusa a imposição de limitações - e é na arte que ela encontra sua 
linguagem e "os surrealistas reconheceram as implicações revolucionárias das descobertas de Freud"3 (idem, p.135).

Esta função crítica está ausente da teoria freudiana, uma vez que para ela a imagem evocada pela "imaginação" reflete apenas um passado subhistórico, sem volta. Na medida em que a civilização depende da inibição da satisfação e das possibilidades de prazer para a manutenção da vida através do trabalho, a idéia de um "princípio de realidade" não repressivo implicaria num "retour en arrière" no desenvolvimento da civilização - a história é hipostasiada numa forma única da civilização.

Entretanto, Marcuse pensa que a realização das reivindicações da "imaginação" em tornar a liberdade e o prazer realidade não levaria a civilização de volta a fases primitivas, pois a civilização não-repressiva depende não do estancamento do "progresso" 4 mas de sua liberação, isto é, o apaziguamento da luta pela existência tornado possível com o "progresso". Esta diferença em relação aos estados anteriores da civilização é que torna possível pensar na realização da "utopia". Mas a questão que Marcuse se coloca é:

A única questão pertinente é saber se podemos razoavelmente considerar um estado da civilização no qual as necessidades humanas sejam satisfeitas de uma maneira tal e na medida em que a mais-repressão $0^{5}$ possa ser suprimida. (idem, p.137)

3 "Reduzir a imaginação à escravidão, mesmo que estivesse em jogo aquilo a que grosseiramente se chama felicidade, é privarmo-nos de tudo o que encontramos, no nosso íntimo mais profundo, de justiça suprema. Somente a imaginação me diz o que pode ser" (Breton apud Marcuse, 1999, p.138).

4 A noção de "progresso" na teoria crítica adquire um conteúdo específico; a crítica do progresso difere de uma recusa ingênua das novas técnicas, isto é, ela não tem como proposta uma volta às fases anteriores de desenvolvimento, numa espécie de nostalgia do passado. Nas palavras de M. Löwy: "[ela] implica uma atitude com relação ao passado que se distingue profundamente dos restauracionistas românticos: o objetivo não é a conservação do passado, mas a realização das esperanças passadas" (Löwy, 1992, p.205)

Marcuse apresenta esta crítica do progresso no seu texto A Noção de Progresso à Luz da Psicanálise; ele faz uma distinção entre "progresso quantitativo", chamado de progresso técnico (que corresponde à forma atual em que ele se dá), e "progresso qualitativo", que é chamado de progresso humanitário (que corresponde à forma em que ele deveria se dar). A questão a ser respondida com esta distinção entre as duas formas de progresso é "se esse progresso contribui realmente para o aperfeiçoamento humano, para uma existência mais livre e feliz" (Marcuse, 2001, pp.112-3).

50 "recalque suplementar" relativo ao interesse de dominação é o que Marcuse chama de "maisrepressão" e o "princípio de realidade" correspondente à sociedade que impõe a "mais-repressão", a fim de manter a dominação frente à real possibilidade de eliminação do trabalho árduo (alienado), chama-se "princípio de rendimento". Esses conceitos pretendem "elucidar a extensão e os limites da repressão dominante na civilização contemporânea" que deve ser descrita "com a ajuda do 'princípio de realidade' específico que rege o desenvolvimento desta civilização" (Marcues, 1963, pp.49-50). Segundo Marcuse: "Através de toda a história da civilização, a coação [pulsional] imposta pela penúria foi aumentada por coações impostas pela repartição hierarquizada da penúria e do trabalho: os interesses de dominação acrescentam um recalque suplementar à organização das [pulsões] sob o reino do 'princípio de realidade'. O princípio de prazer não foi des- 
Ele quer saber se a eliminação da "mais-repressão" não eliminaria também o trabalho e, portanto, a própria civilização, tal como imagina Freud. A possibilidade de eliminar apenas a repressão imposta pelo interesse exclusivo de dominação ("mais-repressão"), deve permitir a formação de relações de trabalho novas e duráveis e não a eliminação do trabalho e da civilização. A realização da "utopia" depende de uma análise dos caminhos que tomariam as pulsões sob a vigência de um "princípio de realidade" não-repressivo.

A primeira das pulsões que Marcuse analisa são as "pulsões de vida", que segundo ele, são as mais "desordenadas".

\section{As Pulsões de Vida: "auto-sublimação da sexualidade em Eros", "sublimação não-repressiva" e "dessublimação da razão"}

Para Marcuse, uma ordem não-repressiva só é possível se as pulsões sexuais podem, pela própria dinâmica e em condições sociais e existenciais transformadas, fundar relações eróticas duráveis entre os indivíduos. É preciso perguntar se essas pulsões, depois da eliminação da mais-repressão, podem desenvolver uma "racionalidade libidinal' que seja, não somente compatível com o progresso, mas que o conduza a formas superiores de liberdade na sociedade (idem, p.174)".

De acordo com a leitura de Marcuse, na teoria freudiana os "obstáculos sociais" impostos às "pulsões sexuais" se devem à necessidade do trabalho na civilização e à necessidade de formação de relações duráveis entre as pessoas: o corpo dessexualizado permite sua utilização enquanto instrumento de trabalho alienado (através da canalização da energia libidinal que lhe é necessária), assim como a convivência em comunidade. Toda diminuição destes "obstáculos sociais" conduziria a sociedade a fases pré-civilizadas.

No entanto, Marcuse argumenta que se o tempo e a energia empregados no trabalho fossem reduzidos, "sem uma manipulação do tempo livre", as bases destes obstáculos sociais à satisfação pulsional seriam também reduzidas: o corpo se ressexualizaria e não seria mais utilizado como instrumento de trabalho. Isto implicaria uma "reativação das zonas eróticas", o "renascimento da sexualidade polimórfica" e o "declínio da supremacia genital". Esta possibilidade de libertação da sexualidade parece, à primeira vista, conduzir à imagem de uma sociedade de "maníacos" ou mesmo à sua

tronado unicamente porque ele trabalhava contra o progresso, mas também porque ele trabalhava contra uma civilização na qual o progresso assegura a sobrevivência da dominação e do trabalho" (idem, p.46, grifo meu) (ver Pisani, 2003, p.56) 
destruição - isto se for concebida apenas enquanto um fato isolado dentro de uma sociedade repressiva.

O fator central para a compreensão da possibilidade de realização desta "utopia" vislumbrada por Marcuse é que este processo não conduz só à libertação da sexualidade mas também uma "transformação da libido" como resultado de uma "transformação social".

O livre desenvolvimento da libido transformada, além das instituições do princípio de rendimento, difere essencialmente da liberação da sexualidade regida no interior do domínio dessas instituições. (idem, p.177)

A liberação da sexualidade no interior do "princípio de rendimento" corresponde à "dessublimação repressiva da sexualidade". 6 Já a transformação da sexualidade através de sua liberação no contexto de uma realidade transformada, não-repressiva, é chamada de "auto-sublimação da sexualidade".

A "auto-sublimação da sexualidade" conduziria à transformação da sexualidade em Eros. Nas condições específicas da realidade transformada a sexualidade tenderia a dar origem a "relações humanas altamente civilizadas": o fim do "primado da genitalidade" e da "dessexualização do corpo" não levariam à destruição das relações sociais. A sexualidade transformada em Eros implica a sua "ampliação qualitativa e quantitativa" no sentido em que a pulsão tomaria por domínio e objeto a própria vida (e neste sentido ela a protegeria) - ou seja, as "pulsões de vida" levariam adiante seu objetivo, tal como definido por Freud em Além do princípio de prazer, de constituir unidades cada vez maiores e de conservar e ampliar a vida. Para Marcuse, a "sexualidade organizada repressivamente" corresponde à repressão de Eros: a "auto-sublimação da sexualidade" significa o restabelecimento da sua função primeira, "o impulso biológico torna-se um impulso cultural" (idem, p.184).

Neste contexto a função das "perversões" também seria modificada: suas manifestações diferem essencialmente quando produzidas numa civilização não-repressiva ou repressiva. Numa civilização não-repressiva as formas assumidas pelas perversões teriam uma função muito diferente das "formas inumanas, coercitivas e destrutivas" que a perversão apresenta na civilização repressiva que estão ligadas "à perversão geral da existência numa civilização repressiva" (idem, pp.177-8).

6 O conceito de "dessublimação repressiva" permite compreender a dinâmica da sociedade contemporânea que, por um lado, possibilita uma maior "liberdade" e satisfação das necessidades, ao mesmo tempo em que, por outro lado, essa "liberdade" atua como um poderoso instrumento de dominação, sendo absorvida pelo sistema, adquirindo a função de manipulação e controle dos indivíduos, de suas consciências, de seus desejos e necessidades (ver Pisani, 2003, p.33-4). 
Também a "sublimação" adquire um novo caráter nesta sociedade transformada: ela se apresenta como "sublimação não-repressiva". A "sublimação", tal como definida por Freud, é chamada por Marcuse de "sublimação repressiva", pois ela implica a dessexualização da pulsão, a inibição de sua meta sexual e o redirecionamento de sua meta para um fim não sexual. Para o autor a "sublimação (repressiva) da sexualidade" difere da "sublimação de Eros" na medida em que a primeira se estabelece no contexto de uma sociedade repressiva e a segunda numa sociedade transformada. A "sublimação" de Eros nesta nova sociedade é "sublimação não-repressiva" e ela representa a possibilidade de uma "sublimação" sem dessexualização.

É evidente que sob o domínio do princípio de realidade atual, uma sublimação não-repressiva só pode aparecer pelos seus aspectos marginais incompletos: sua forma plenamente desenvolvida seria a sublimação sem dessexualização. O instinto não é desviado de seu objetivo. Ele é satisfeito em atividades e relações que não são sexuais no sentido da sexualidade genital organizada mas que são entretanto libidinais e eróticas. (idem, p.182)

A sexualidade liberada de sua limitação espacial não seria desviada nem impedida de se realizar, mas, enquanto um impulso coletivo, que procura a manutenção da vida e da sociedade, enquanto "pulsão de vida", Eros, ela transcenderia seu objeto e satisfação imediatos em favor da coletividade. Esta nova modalidade de "sublimação" não levaria à extinção da cultura, uma vez que continua havendo sublimação, como nos mostram estas duas citações presentes em Eros e Civilização:

[A sublimação não-repressiva] deve ser um processo supra-individual (...). Enquanto fenômeno individual isolado, a reativação da libido não leva à civilização superior mas, à neurose. (idem, p.183)

A diferença entre uma neurose e uma sublimação reside evidentemente no aspecto social do fenômeno. Uma neurose isola, uma sublimação une. Pela sublimação, alguma coisa nova se cria: uma casa, uma comunidade, um instrumento - e se cria no grupo para ser utilizado pelo grupo. (G. Rohein apud idem, p.183)

A possibilidade da "sublimação não-repressiva" implica que esta possa agir sobre um sistema de relações libidinais crescentes e duráveis: as relações de trabalho.

Esta possibilidade do "trabalho prazeroso" é a base para a nova sociedade. Apesar de Freud não diferenciar "trabalho alienado" e "trabalho não alienado", a possibilidade do trabalho proporcionar prazer "não lhe é estranha". Marcuse diz que em Psicologia de massas e análise do ego Freud parece reconhecer a possibilidade da libido se ligar à "satisfação das grandes necessidades vitais": haveria na teoria freudiana uma contradição no que 
se refere à questão da luta pela existência ser libidinal ou anti-libidinal. Mas, para Marcuse, o próprio fato de Freud estabelecer uma ligação entre trabalho e sexualidade, entre a "atividade humana" e a "organização das pulsões", já abre a perspectiva para imaginar a possibilidade do trabalho não ser simplesmente fonte de desprazer, mas de poder ser investido libidinalmente numa sociedade não-repressiva.

A possibilidade de uma tendência erótica no trabalho é dada pelo atual nível de desenvolvimento das forças produtivas. De acordo com a leitura que Marcuse faz da teoria freudiana, a modificação repressiva das pulsões se impõe como necessária para possibilitar a luta pela existência e a manutenção da vida. Neste sentido, a impossibilidade da libertação do "princípio de prazer" implica na "suposição de que a penúria é permanente".

Mas se numa nova etapa da civilização a luta pela existência pode ser apaziguada, em conseqüência do progresso técnico que possibilitaria a vitória sobre a escassez, então não há porque negar a possibilidade do trabalho investido libidinalmente. A mecanização da produção permitiria uma diminuição no tempo desperdiçado na manutenção da sobrevivência, o que libertaria a energia sexual de sua limitação espacial necessária para o trabalho - e uma vez que a sexualidade transformada em Eros toma como objeto de satisfação a própria vida e sendo o trabalho parte integral na sua constituição e na sua auto-preservação, então ela também tomará o trabalho como fonte de satisfação. As condições sociais alteradas criariam uma base pulsional para a transformação do trabalho em "atividade lúdica". Nestas novas condições o trabalho não teria mas um fim exterior, isto é, a manutenção do sistema de dominação: ele seria transformado em "jogo", proporcionando satisfação em si mesmo.

Uma modificação na estrutura instintual (...) conduz a uma alteração no valor instintual da atividade humana, qualquer que seja seu conteúdo (...) Se o trabalho fosse acompanhado de uma reativação do erotismo pré-genital polimórfico, ele tenderia a tornar-se satisfação em si sem perder seu conteúdo de trabalho. É exatamente esta reativação do erotismo polimórfico que apareceu como conseqüência da vitória sobre a penúria e a alienação. (idem, p.187)

Esta questão do "trabalho" apresenta sua plena significação quando colocada em relação à crítica do revisionismo neofreudiano. ${ }^{7}$ Marcuse critica a formulação de Ives Hendrick que atribui ao ser humano um "instinto de

7 O Revisionismo Neo-freudiano foi uma corrente de pensamento derivada da teoria freudiana e que teve grande repercussão nos anos 50 e 60 nos Estados Unidos. Dentre os seus principais representantes estão Eric Fromm e Karen Horney, entre outros. No final do livro, Marcuse desenvolve em um epílogo sua critica ao Revisionismo. 
habilidade" específico: segundo Hendrick as energias necessárias para o trabalho provêm deste instinto, cujo objetivo é modificar e controlar o meio. A satisfação deste instinto estaria garantida pela possibilidade de satisfação através do trabalho (o trabalho produziria prazer na satisfação deste instinto). Para Marcuse, se o trabalho em si propicia prazer, então a relação estabelecida por Freud entre sexualidade e trabalho (entre prazer libidinal e trabalho árduo) perde sua significação.

Numa realidade governada pelo "princípio de rendimento" (ou "princípio de desempenho", conforme a tradução brasileira) a possibilidade de obtenção de prazer pelo trabalho torna-se repressiva - e a afirmação desta possibilidade torna-se "ideológica". Os revisionistas aceitam o trabalho tal como estabelecido (trabalho alienado) e, mais do que isso, o trabalho aparece como fonte de prazer e gratificação. Para Marcuse, o trabalho alienado não satisfaz as necessidades dos indivíduos, suas próprias pulsões e faculdades, mas "cumpre uma função pré-estabelecida" - é preciso fazer a crítica desta forma de trabalho: "Associar o desempenho em linhas de montagem, em escritórios e lojas, com necessidades pulsionais, é glorificar a desumanização como prazer" (idem, p.191-2).

Outro fator importante na constituição de uma civilização não-repressiva é a "dessublimação da razão". Ela implica a possibilidade de a "razão" se tornar também "objeto direto" de investimento libidinal, o que daria origem a uma nova idéia de "razão". Se a "sublimação" (repressiva) da razão conduz à dessexualização, ou seja, à separação dos conteúdos sensíveis na oposição entre faculdades superiores e inferiores, razão e sensibilidade (estabelecida na história do pensamento ocidental), então a "dessublimação da razão" implicaria a "ressexualização" dessa razão e o surgimento de uma "razão sensível" e a uma "nova sensibilidade". Na condição de uma civilização não-repressiva, em que as relações de trabalho tenham sido transformadas, a tendência peculiar a Eros em buscar prazer se estende até a esfera espiritual: "nada na natureza de Eros justifica a noção segundo a qual o instinto é limitado ao domínio corporal" (idem, p.183).

Portanto, Marcuse justifica a possibilidade da modificação não-repressiva das pulsões na civilização não-repressiva pelos processos de "auto-sublimação da sexualidade" e da "dessublimação da razão", enquanto processos resultantes da conquista sobre a escassez. A transformação da estrutura pulsional, das relações de trabalho, da "razão" e da "sublimação" (a eliminação de seus conteúdos repressivos) modificaria a atitude do ser humano em relação à natureza e aos outros seres humanos, de modo que seria completamente oposta à atitude que caracteriza atualmente a civilização ocidental.

A transformação da sexualidade em Eros e a sua extensão às relações de trabalho pressupõem para Marcuse uma reorganização racional de um 
aparelho industrial enorme e a utilização construtiva da energia destrutiva. Marcuse exemplifica a possibilidade deste tipo de relação do ser humano com o meio, que não se baseia na dominação e exploração, através da antropologia, apresentando o exemplo da sociedade Arapesh descrita pela antropóloga Margareth Mead que tem como traço particular a ausência de conflito com a natureza e entre seus membros.

Mas já que Marcuse se propôs a aceitar todos os conceitos da teoria freudiana, a possibilidade de estabelecer uma civilização não-repressiva precisa ser analisada frente ao maior dos empecilhos para sua formulação: as "pulsões de morte".

\section{As pulsões de morte}

Para Freud, o maior obstáculo que enfrenta a civilização é o controle da tendência inata ao ser humano que o conduz à agressão e às manifestações desta tendência que se acham ligadas às manifestações de Eros (é por isso que a sexualidade também não pode ser liberada, pois liberaria as tendências agressivas que são unidas a ela). Marcuse afirma que a hipótese de Freud, de que a agressão é inata ao ser humano e que é um empecilho na constituição de uma sociedade livre, é de grande serventia para a manutenção do "princípio de rendimento", pois torna todo protesto insensato e inútil.

No texto de 1977, Ecologia e Crítica da Sociedade Moderna, Marcuse afirma que a negação da possibilidade da transformação das pulsões "testemunha o grau ao qual esta objeção sucumbiu a uma ideologia conformista" (Marcuse, 1999, p.154) - esta objeção apresenta a dominação e a agressão como "leis da natureza". Entretanto, contra a tendência inata à agressão atribuída por Freud, Marcuse argumenta:

Contra esta ideologia, insisto que não há algo como uma natureza humana imutável. Além e acima do mundo animal, os seres humanos são seres maleáveis, corpo e mente, até mesmo em sua estrutura pulsional. (idem, p.154)

Na teoria freudiana as "pulsões de morte" constituem uma tendência do organismo a buscar o estado de ausência de tensão: segundo esta hipótese desenvolvida em Para além do princípio de prazer, na medida em que a matéria viva se originou da matéria inorgânica ela tende a retornar a esse estado. Essas pulsões se dirigem no sentido da autodestruição e destruição do meio, como um caminho mais rápido para a morte, que é o estado de ausência total de tensão e desprazer.

Já de acordo com a hipótese de uma civilização não-repressiva desenvolvida por Marcuse, numa sociedade em que a luta pela existência tenha 
sido praticamente eliminada (devido às conquistas do progresso técnico) e cuja organização tenha se tornado "racional" (no sentido forte do termo), a busca das pulsões pela ausência de tensão e de sofrimento deve estancar, já que essa tensão e esse sofrimento seriam eliminados. A vida estaria organizada de tal forma que as pulsões perderiam seu "caráter regressivo" - o "princípio de Nirvana" convergiria com o "princípio de realidade" não-repressivo.

Se o fundamental da [pulsão] não é a cessação da vida, mas da dor, ausência de tensão, paradoxalmente, o conflito entre a morte e a vida é reduzido quanto mais a vida se aproxima do estado de satisfação. O princípio de prazer e o princípio de Nirvana convergiriam. (idem, p.203)

A possibilidade de uma transformação na organização pulsional desenvolvida por Marcuse apóia-se na hipótese de Fenichel segundo a qual, se as pulsões possuem uma "natureza comum", tal como afirma Freud em Para além do Princípio de Prazer, então há uma energia deslocável, neutra, ora podendo se aliar à tendência erótica, ora à tendência destrutiva: esta posição permite que, no curso de seu desenvolvimento, as pulsões possam ser diferenciadas por influências externas (Marcuse, 1963, p.37).

Na medida em que Eros se livra da "mais-repressão" imposta pela dominação, que exige a transformação repressiva da sexualidade, e que as "pulsões de morte" não são mais impelidas a escapar do estado de sofrimento e tensão impostos pela realidade, estas pulsões perderiam em grande parte a necessidade de "regressão": a "natureza conservadora" das pulsões desapareceria "num presente apaziguado".

\section{Memória e utopia}

Marcuse impõe uma condição necessária para a possibilidade da transformação do "princípio de realidade" repressivo: a liberação do conteúdo recalcado da memória, enquanto "veículo da libertação". A civilização repressiva impõe constantemente a resignação e o "esquecimento" (recalque da memória) como condições de sua sobrevivência, já que a civilização não se "redimiu" das injustiças e dos sofrimentos passados: assim ela pode continuar se reproduzindo e reproduzindo a injustiça e a escravidão. ${ }^{8}$ Esta "faculdade do esquecimento" está ligada à submissão e à resignação, que são constantemente incentivadas pela "moral civilizada".

\footnotetext{
8 Aqui reside uma das grandes contribuições de Freud para o pensamento social, já que a história da humanidade como dominação e sofrimento não é esquecida e apagada, como acontece no revisionismo
} 
Esquecer é também esquecer o que não podia ser esquecido para que a justiça e a liberdade triunfem. Esta faculdade reproduz as condições que reproduzem a ordem e a escravidão: esquecer os sofrimentos passados, é esquecer as forças que os causaram, e esquecer sem vencê-las. As feridas que se curam com o tempo são também aquelas que contêm o veneno. (idem, p.201)

A liberação desse conteúdo recalcado da memória é a condição da "sublimação não-repressiva" na medida em que ela se traduza em "ação histórica".

(...) a lembrança não constitui uma arma real, a menos que se traduza em ação histórica: a luta contra o tempo passa a ser um momento decisivo na luta contra a dominação. (idem, p.202)

A aliança entre "tempo" e "repressão" garante a manutenção da realidade repressiva, pois faz com que os indivíduos esqueçam os sofrimentos passados, assim como as satisfações. A "força crítica" de Eros reside na sua oposição ao prazer temporário e limitado, na tentativa de vencer o tempo e restabelecer a satisfação integral - o prazer e a satisfação são intemporais e não admitem limitação e controle.

O tempo só perde seu poder repressivo quando a memória do passado é resgatada. Para Fredric Jameson, a obra de Marcuse "lança os fundamentos para a possibilidade do pensamento utópico" através da valorização da memória: segundo ele, a memória da satisfação está na origem de todo pensamento, e o impulso para recuperar a satisfação passada é a força oculta por detrás do processo de pensamento. É somente através dessa restauração do conteúdo recalcado da memória que a lembrança pode se traduzir em "ação histórica" - a memória teria, neste sentido, um papel político.

A energia primária da atividade revolucionária deriva dessa memória de uma felicidade pré-histórica. A perda ou repressão do sentido de conceitos como felicidade e desejo toma a forma de uma espécie de amnésia ou embotamento desmemorisado, que a atividade hermenêutica, a estimulação da memória como negação do presente, como projeção de utopia, tem como função dissipar, restaurando nossos impulsos e desejos vitais. (Jameson, 1985, p.92)

A "utopia" formulada por Marcuse em Eros e Civilização, a possibilidade de um desenvolvimento não-repressivo das pulsões, é fundamentada na transformação social. Entretanto, não basta apenas a preocupação com a base infraestrutural desta transformação sócio-econômica - não basta uma reorganização das forças produtivas, tal como realizada pelo marxismo soviético. ${ }^{9}$ A novidade no seu pensamento social é que ele rompe com um de-

9 Conforme a crítica desenvolvida em seu livro "Marxismo Soviético", em 1958 
terminado marxismo ortodoxo ao introduzir a preocupação com a base humana do desenvolvimento do capitalismo para o comunismo. Sem esta transformação subjetiva, na cultura, nos padrões de comportamento, na relação entre os indivíduos e entre esses e seu meio, a sociedade realmente "comunista" é impensável.

Ao propor a crítica à racionalidade dominante, à razão enquanto Logos de dominação, Marcuse propõe a "refundação" e a "reformulação" da idéia de razão e não sua eliminação: é uma determinada organização política e econômica que impede o desenvolvimento da razão em todas as suas potencialidades e não a razão per se. A razão aberta à sensibilidade e a sensibilidade aberta à razão levariam a um novo estágio da civilização, essencialmente oposto ao atual, no qual as pulsões poderiam seguir um curso nãorepressivo e, nesse processo, sustentariam a vida ao invés de destruí-la.

A leitura que Marcuse realiza da obra de Freud em Eros e Civilização é muito singular: ele utiliza apenas aqueles elementos que lhe interessam, pois ele parte de um objetivo e uma perspectiva teórica definidas de antemão. O que procuramos mostrar neste artigo é a leitura extremamente original que ele realiza, sem nos atentarmos para os problemas e deformações que, conforme afirmam muitos de seus críticos, Marcuse impôs ao discurso psicanalítico (como a não distinção entre recalque e repressão, pulsão e instinto $^{10}$ ). Encerramos este artigo com uma citação de Jameson onde ele sintetiza com muita perspicácia a contribuição da interpretação filosófica do pensamento de Freud realizada por Marcuse:

[A obra de Marcuse] pode servir como amostra objetiva de algumas das formas que uma hermenêutica marxista dispõe para desenvolver a dimensão política autentica a textos disparatados que se acumulam no livro de nossa cultura: não através de uma fácil interpretação simbólica ou alegórica, mas lendo o próprio conteúdo e impulso formal dos textos como figuras - seja da integridade psíquica, da liberdade, ou do movimento em direção à transfiguração utópica - do desejo revolucionário irreprimível. (idem, pp.124-5)

PISANI, M. M. Utopia and psychoanalysis on Herbert Marcuse. Trans/Form/Ação, (São Paulo), v.29(2), 2006, p.203-217

- ABSTRACT: In the present article is given an important idea prescribed by Marcuse in the second part of his Eros and Civilization. A Philosophical inquiry into Freud. (1955) - the non-repressive transformation of the instincts in a trans-

10 Dentre as críticas mais relevantes se destacam as de Laplanche (1992) e Bento Prado Jr. (1990). Para mais informações a respeito destas críticas ver Pisani, 2003, p.80-83. 
formed society. The utopia developed in this book is based in the reinterpretation of some of his main conceptions of the freudian theory and characterize the singularity of his ideas and of his general thinking.

- KEYWORD: Marcuse; Imagination; Eros (Instinct of Life); Thanatos (Instinct of Death); Memory; Utopia.

\section{Referências bibliográficas}

FREUD, S. Além do Princípio de Prazer. Rio de Janeiro: Imago, 1998.

FREUD, S. Le Malaise dans la Culture. Paris: Quadrige, 2000.

JAMESON, F. Marcuse e Schiller in Marxismo e Forma. São Paulo: Hucitec, 1985.

LAPLANCHE, J. Notes sur Marcuse et la Psychanalyse. In La Révolution Copernicienne Inachevée. Paris: Aubier, 1992.

LAPLANCHE, J. e PONTALIS, J. B. Vocabulário de Psicanálise. São Paulo: Martins Fontes, 2001

LÖWY, M. A Crítica do Progresso em Adorno. in Lua Nova, n²7. São Paulo: Marco Zero, 1992

MAAR, Wolfgang Leo, Marcuse: em busca de uma ética materialista. In: Cultura e Sociedade. Rio de Janeiro: Paz e Terra, 1998.

MAAR, W.L. Marcuse: as bases materiais da dominação ideológica. In: Olhar. vol 2, ano I, 1999

MARCUSE, Herbert, Eros et Civilization. Paris: Les Editions Minuit, 1963.

MARCUSE, H. A Ideologia da Sociedade Industrial. Rio de Janeiro: Zahar, 1969.

MARCUSE, H. Eros e Civilização: uma interpretação filosófica do pensamento de Freud. Rio de Janeiro: LTC - livros técnicos e científicos editora S.A, 1999.

MARCUSE, H. Cultura e Psicanálise. tradução de Wolfgang Leo Maar, Isabel Loureiro e Robespierre de Oliveira. São Paulo: Paz e Terra, 2001.

PISANI, Marilia Mello, Marcuse e Freud: uma interpretação polêmica - um estudo de "Eros e Civilização". Dissertação de mestrado. São Carlos: Ufscar, 2003.

PRADO JR., Bento. Entre o Alvo e o Objeto de Desejo: Marcuse crítico de Freud. In NOVAES, A. (org.). O Desejo. São Paulo: Companhia das Letras, 1990.

WIGGERSHAUS, Rolf. L' École de Francforte: histoire, développement, signification. Paris: PUF, 1993. 